\title{
The Relationship between Big-Five Personality Traits, English Language Proficiency Scores on IELTS, and Academic Success of Iranian Foreign Students
}

\author{
Shiva Seyed Erfani \\ Islamic Azad University, Roudehen Branch, Iran \\ Hoda Mardan \\ Islamic Azad University, Roudehen Branch, Iran
}

\begin{abstract}
There is a potential to supply personality as a psychological factor in terms of the Big-Five Model including Extraversion, Agreeableness, Consciousness, Openness to Experience, and Neuroticism. This study was an attempt to examine the relationship between Big-Five personality traits, English language proficiency scores on IELTS, and academic success of Iranian foreign students. The participants of the study included 202 Iranian students (126 males and 76 females) who studied at English speaking universities in different countries including Armenia, Austria, Australia, Canada, Cyprus, Germany, Hungary, India, Italy, Malaysia, New Zealand, Pakistan, Philippines, Sweden, the United Arab Emirates, the United Kingdom, Ukraine, and the United States of America. The necessary data for this study were collected from participants' first-semester academic reports to measure the degree of academic achievement, academic IELTS certificates to determine the language proficiency of candidates, as well as International Personality Item Pool Big-Five inventory to identify the participants' personality traits. The data were gathered via different communication tools. The correlational analyses showed that there were significant relationships amongst personality traits and Iranian foreign students' language proficiency. Neuroticism was the only psychological trait, negatively correlated with both language proficiency and academic success of Iranian foreign students. The study also revealed that there was a high correlation between the scores on IELTS and academic success of Iranian foreign students. Finally, multiple regression analysis indicated the causality among the Big-Five personality traits, English language proficiency score on IELTS, and academic success of Iranian foreign students. These bear testimony to the idea of cognitive approach in that one's underlying mental processes are in charge of second language learning process.
\end{abstract}

Index Terms - academic success, big-five personality traits, IELTS, language proficiency

\section{INTRODUCTION}

Annually, thousands of learners from various cultural, economic, educational, social, and psychological backgrounds intend to study in other countries. Continuing the academic education in a foreign country provides learners with opportunities to experience a new type of culture, meet different people, study novel perspectives or utterly different subjects, and better prepare for an occupation in an increasingly globally integrated world.

In recent decades, psychologists have recognized factors such as personality traits and learning styles involved in individual academic performances (Busato, Prins, Elshout, \& Hamaker, 2000; Chamorro-Premuzic, \& Furnham, 2003). This is in accordance with the cognitive psychology which is concerned with the ways information is processed in human mind. Turning to cognitive theory, learning a language is the result of internal mental activity that takes place in the same manner as learning in the other general human tasks. This involves cognitive skills to be acquired in a very complex way (Ausubel, 2012; Anderson, 1992; Ellis, 2008; McLaughlin, 1987; Tarone, 2007).

There is a body of evidence suggesting that nearly all personality measures can be put and simplified under the section of Five-Factor Model (FFM) of personality, which as a result has been named the "Big-Five" (Goldberg, 1990). The flexibility of the Big-Five is known to communalize right through all cultures and stay quite constant (McCrae, \& Costa, 1997).

On the other hand, the validity criterion for ability tests is related to academic performance for over a century, and the number of studies showed that it is possible to explain individual differences in academic performance by personality traits (Brody, 2000; Cronbach, 1949).

International English Language System (IELTS) is one of several English proficiency tests used by tertiary institutions in Australia, Britain, Canada and New Zealand who assess the English language proficiency of international students. The relationship between English language proficiency and the academic success of international students in 
different context in other words, the issue of predictive validity of the test such as IELTS has its importance as there have been recently giant leaps in the number of applicants from non-English speaking countries that take IELTS as the gate way to international universities (Seyed Erfani, 2011).

\section{PRoblem AND PuRPose}

The growth in the number of international students has led to controversies on the requirements of English language proficiency and higher education. From the teaching point of view, most universities have more international and nonEnglish speaking students than ever (Woodrow, 2006). IELTS, then, is an applicable tool to assess the types of skills usually needed in tertiary settings and offers outlined scores on subtests of speaking, writing, listening, and reading.

During the last decades, Iranian students have been increasingly willing to study abroad. In accordance with the Tabnak News in April 2014, there are around 120000 Iranian students who study abroad at undergraduate, postgraduate, philosophy of doctorate, and other levels. The major struggle for them would be to obtain the required IELTS score to promptly apply for a university course and to have improved academic performance in their programs. To make such goal come true, there are numerous factors one critical of which is individuals' personality. If well aware of their personality traits and the relationship they have with the test performance, the learners could apply appropriate strategies to heal the personality and boost test performance eventually. However, the assumed advantages of personality traits should be empirically verified. As Arnold (1999) argues, personality traits and the affective side of human being in general are always expressed through the human knowledge and in particular second language learning.

There are many personality and affective factors which have queued to be explored in terms of their relationship with language learning, test performance, and academic performance. Among such factors is the Five-Factor Model made up of the aspects of Extraversion, Agreeableness, Conscientiousness, Openness to Experience, and Neuroticism. (Ehrman, Leaver, \& Oxford, 2003).

The question to be addressed here is if there does any significant relationship exist between personality traits, IELTS results, and academic performance of Iranian foreign students studying at English speaking universities aboard. The main objective of the present study was to look at the degree of the relationship between Big-Five personality traits, English language proficiency scores on IELTS and academic success of Iranian foreign students who have studied abroad.

The present study aimed to investigate one of the controversial topics in the domain of cognitive psychology, BigFive personality traits, to see how they could be applied as a tool for improving and predicating how Iranian foreign students could perform on language proficiency tests especially IELTS and their later academic courses. This study was conducted in order to support the claims made concerning the educational values of Big-Five personality traits through exploring their relationship with the IELTS as an English language proficiency test. As a result the variables of the study were assigned as the Big-Five personality traits including Extraversion, Agreeableness, Conscientiousness, Openness to Experience, and Neuroticism as the predictor variables on one side and Iranian foreign students' Language Proficiency scores on IELTS as well as their academic success as the dependent ones on the other side. Finally, the study was an attempt to introduce a rather potential way to predict the scores on IELTS and the academic success of the Iranian foreign students through a psychological tool that is hidden inside a learner, and is mostly unknown to the teachers, material developers, and curriculum developers.

\section{RESEARCH QUESTIONS}

1) Is there any significant relationship between Big-Five personality traits and language proficiency scores on IELTS of Iranian foreign students?

2) Is there any significant relationship between Big-Five personality traits and academic success of Iranian foreign students?

3) Is there any significant relationship between academic success and language proficiency scores on IELTS of Iranian foreign students?

4) Is there any significant causality among Big-Five personality traits, language proficiency scores on IELTS, and academic success of Iranian foreign students?

\section{REVIEW OF LITERATURE}

Cognitive psychology deals with the question how human mind tends to think and learn. It takes learners as active participants who rely on different strategies to become involved in learning processes which naturally take place as complex phenomena interconnected with a network of factors that internationally come into operation. Learners bring strategies learning strategies to the classrooms. This originates from the particular learning styles learners do possess. In term, the individual differences are woven with the personality traits that altogether determine the way of learning and the ups and downs the learners might come across based on their personal features. With respect to the cognitive psychology, the rate of such traits varies cross-individually; then it is of great importance to see how far students might differ in such traits. 
The cognitive perspective of personality is the idea that people are who they are because of the way they think, including how information is attended to, perceived, analyzed, interpreted, encoded and retrieved. In this regard, the major objective of research on individual differences was to forecast which learners would succeed (Ellis, 2004). According to Dörnyei (2005), one of the most important reasons for being more successful is personality or 'enduring personal characteristics that are assumed to apply to everybody and on which people differ by degree'. Here, personality is an important item for describing individual differences in second language learning. Based on another definition, personality refers to the unique characteristics of an individual person; display of characteristic adaptations; unique identifications about life and cultural differences (Hogan, Hogan \& Roberts, 1996; McAdams \& Pals, 2006).

A general agreement can be found within the personality and individual difference literature that personality is best depicted by a five-factor model (e.g. Costa \& McCrae, 1992, 1995; De Raad \& Schouwenburg, 1996; Furnham, 1996). The Big-Five factors are usually marked as Extraversion, Agreeableness, Conscientiousness, Openness to Experience, and Neuroticism (Duff, Boyle, Dunleavy \& Ferguson, 2004).

The Big-Five taxonomy has never been proposed as an inclusive personality theory; it was rather developed to build structural associations among personality traits (Goldberg, 1993). Hence, as quiet normal with structural models, it introduces a version of personality that is more descriptive than explanatory, tends to stress the predictabilities in behavior rather than inferred dynamic and developmental processes, and focuses on variables instead of individuals or types of individuals (John \& Robins, 1993, 1998).

Besides, the Big-Five taxonomy of trait represents a conceptual basis to support investigating these theoretical issues. Funder (2001) asserts that extraversion copes with activity and sociability. Extraverts are usually quite sociable (friendly and sociable), but are also domineering (dominant and aspirant) and active (contumelious and assertive). Agreeableness refers to reflecting likeability and friendliness. Agreeable people are cooperative (trusting of others and caring) as well as being likeable (good natured, cheerful, and gentle) (Judge, Higgins, Thoresen \& Barrick, 1999). Conscientiousness deals with dependability and will to achieve. Conscientiousness is unfolded in three related angles achievement orientation (hardworking and persistent), dependability (responsible and careful), and orderliness (planful and organized). Openness has to do with imaginativeness, broad-mindedness and artistic sensibility. Openness to experience is characterized by intellectance (philosophical and intellectual) and unconventionality (imaginative, autonomous, and nonconforming). Neuroticism, or the nervous system is the most universal feature among personality measure, as Costa and McCrae (1988) note. It is distinguished in nearly every dimension of personality. It is concerned with adjustment vs. anxiety. It points to at least two related orientations. One deals with unrest (inconsistency and stress ability) and other deals with one's health and well-being (low self-confidence and depression). However, neuroticism usually refers to a negative or sometimes no psychological adjustment and emotional instability (Judge et al., 1999).

Language proficiency refers to the degree of skill with which a person can use a language, similar to how well a person can read, write, speak or understand a language. IELTS stems from the notion of communicative competence which targets the students' knowledge of how to use the linguistic, sociolinguistic, lexical, and grammatical aspects of a language. Academic performance has been one of the main factors of interest in education and psychology. Some of the earliest modern psychological research is conducted with the aim to identify the factors that predict academic performance (Poropat, 2011). Academic performance is mostly measured by Grade Point Average (GPA) of the first and subsequent semester (Woodrow, 2006). The question regarding whether IELTS marks can be used as a predictive score for a student's academic success has been debated by various academics in the past (Bayliss \& Ingram, 2006).

\section{METHOD}

This study sought to investigate whether Iranian foreign students' big-five personality features were correlated with their IELTS score and academic performance, and if so, which traits brought about more relationship and more prediction ability. On the other hand, the study looked at not only the relationship between IELTS scores and academic success of Iranian foreign students but also the causality among the personality traits, IELTS scores and academic success of Iranian foreign students.

Participants

The participants of this study included 202 Iranian foreign students in which 126 of them were male and 76 were female, aged over 18 year-old, where 109, 73, and 20 of the students were at undergraduate, graduate, and postgraduate levels respectively. They were Iranian students from different majors (Figure 1) studying in English speaking universities in Armenia, Australia, Austria, Canada, Cyprus, Germany, Hungary, India, Italy, Malaysia, New Zealand, Pakistan, Philippines, Sweden, UAE, UK, Ukraine, and USA. 


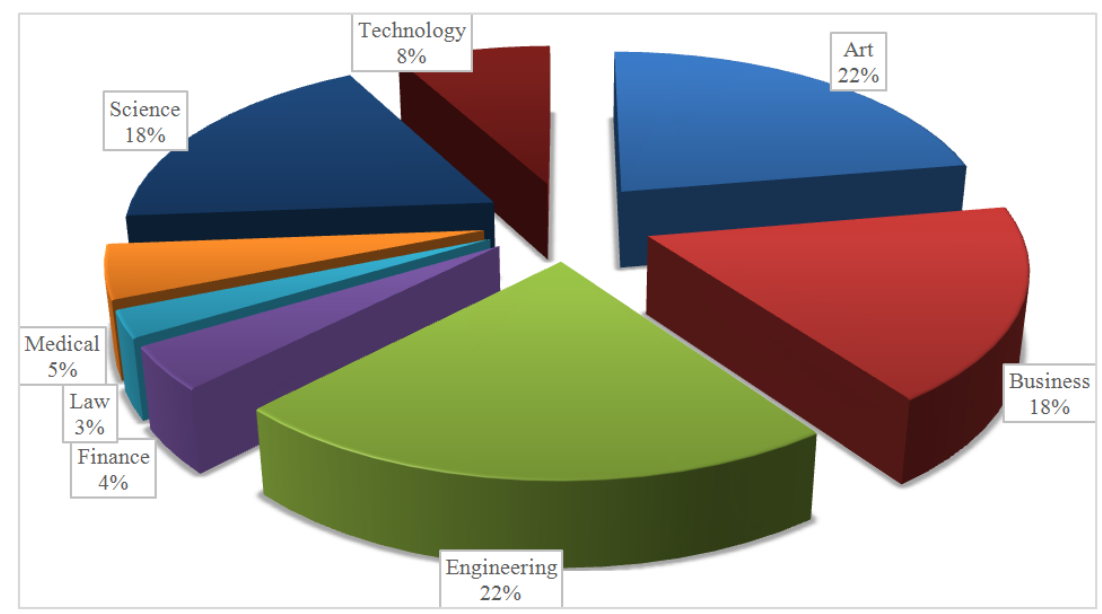

Figure 1. Participants' majors

Figure 2 shows the countries in which the participants were studying or graduated from with their percentages.

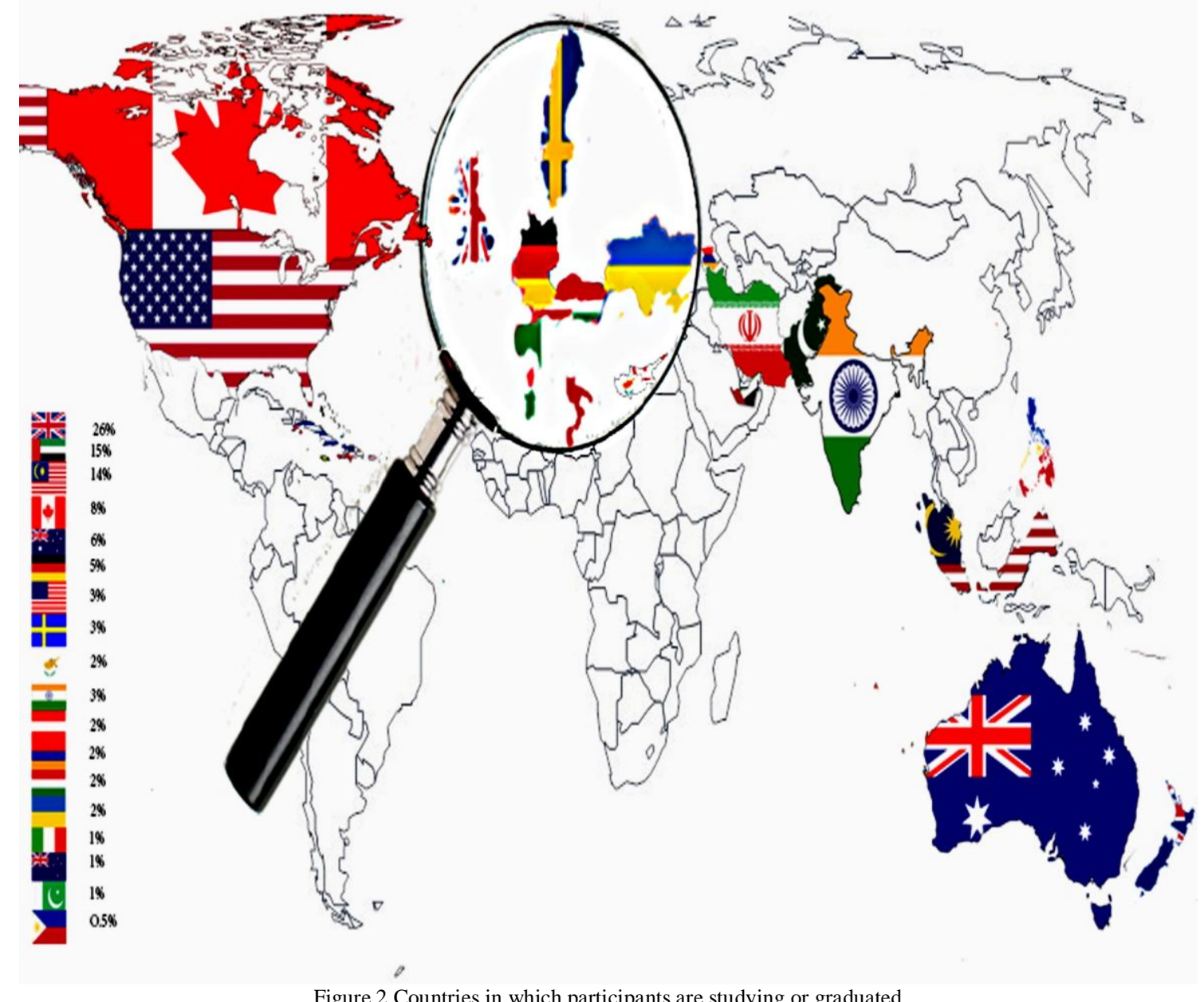

The participants had already taken the academic IELTS and obtained the required score for the universities, they were also required to pass the first year of the program at the related universities.

\section{Instruments}

International Personality Item Pool Big-Five: The International Personality Item Pool Big-Five personality factor IPIP (Goldberg, 2001) was employed to operationalize the personality traits of the participants. The questionnaire included the 50-item version including 10 items for each of the Big-Five personality factors which are in sentence fragment form on a Likert scale of agreement: Extraversion (e.g., I am the life of the party), Agreeableness (e.g., feel little concern for others), Conscientiousness (e.g., I am always prepared), Emotional Stability (e.g., I get stressed out 
easily) and Intellect (e.g., I have a rich vocabulary). It aided the participant to understand why they acted the way they did and how their personality was structured.

Below is a description of each trait and scoring procedure according to Goldberg (1992) and theoretical perspective of the study.

a. Extroversion (E) is the personality trait of attempting to find fulfillment from sources outside the self or in community. High scorers tend to be very social while low scorers prefer to work on their projects alone.

b. Agreeableness (A) shows how much candidates adjust their manner to suit others. High scorers are commonly polite and like people. Low scorers tend to 'tell it like it is'.

c. Conscientiousness (C) is the personality feature of being honest and hardworking. High scorers tend to follow regulations and prefer clean homes. Low scorers may be untidy and trick others.

d. Openness to Experience $(\mathrm{O})$ is the personality feature of searching new experience and intellectual pursuits. High scores may day dream a lot. Low scorers may be very down to earth.

e. Neuroticism $(\mathrm{N})$ is the personality feature of being emotional.

Academic IELTS Certificate: English Language proficiency measured by the academic IELTS test score appeared on the certificate was utilized in this study. Academic IELTS score was selected inasmuch as in terms of the course the Iranian students are required to obtain the required score of language proficiency level to be accepted in a foreign university.

Academic Report: In order to prove the academic performance, the participants' first-semester academic reports were used to measure the degree of academic achievement. Academic achievement of the participants was measured via GPA in the first academic year. Some students had only one mean GPA statistic for one semester. The students' semester academic reports in each university were different. There were in numerical marks, letter grades or percentage. In order to compare the GPA's, all of the outcomes were coded into scores of 0-5 as shown in table 1; they were hidden to coded scores.

TABLE1

CODED SCORE OF ACADEMIC REPORTS

\begin{tabular}{|c|c|c|c|}
\hline Numerical Mark & Letter Grades & Percentage & Coded Score \\
\hline $85-100$ & High Distinction HD & $85-100$ & 5 \\
\hline $75-84$ & Distinction DI & $75-84$ & 4 \\
\hline $65-74$ & CR Credit & $65-74$ & 3 \\
\hline $50-64$ & $\begin{array}{l}\text { PA, PX, APL,T,TT (Pass, Approved prior learning or Credit } \\
\text { Transfer) }\end{array}$ & $50-64$ & 2 \\
\hline $0-49$ & $\begin{array}{l}\text { N,NN (Fail), DNS (Did not sit), RWT (Result withheld) } \\
\text { W,WI(Withdrawn) }\end{array}$ & $0-49$ & $\begin{array}{l}1 \\
0\end{array}$ \\
\hline
\end{tabular}

Communication tools: What's app and Viber as instant messages applications and social networks of Facebook and Linkedin were used to connect to the Iranian foreign students.

\section{Design}

This descriptive research had an ex-post-facto design with a survey method in which the existing relationships between the Big-Five personality traits, academic IELTS scores, and academic success of Iranian foreign students were investigated.

\section{Procedure}

At the first place, it was necessary for every participant to be an international student out of Iran. In this regard, there was a hardship as it was not that easy to access them. Second, the participants were supposed to take part in academic IELTS, while there had been many sitting different versions of TOEFL.

However, the most challenging area was to persuade the participants with the above requirements to provide the researcher with both their academic IELTS certificate and academic report. The participants of the present study were invited randomly from the universities of the above mentioned countries via emails sent to Iranian student groups and asked to attend the orientation sessions in person by traveling to the UAE and the UK in which they were studying different majors.

Prior to taking any steps, any participant had to undergo an orientation session which was to introduce the project, explain the purpose, elaborate on how important it was to fill out the questionnaire accurately, and answer the questions frequently asked on the items of the questionnaire. Upon receipt of the acceptance email from volunteer candidates, they were asked to fill out the IPIP Big-Five, and send a copy of their academic IELTS certificates and first year academic reports. Instant messaging applications were used to contact and call the candidates who were studying abroad via communicative tools requesting they fill out the questionnaire online. The participants were called by some companies like Armansis, Hamta Rah Iliya, UK Study, and K1SPUK that work as recruitment agents and advise students in the UK. In addition, a part of them were gathered from International companies like Ava Trading Company, Avrand Plastic, Arzesh Holding, DIDI Water and MazMaz with employees who graduated from English speaking universities. Also, they were contacted via social network sites and email by offering gift cards and free online English sessions. On the other hand, some of the data were collected directly by traveling to the UAE and the UK in person by an orientation among Iranian students communities. 
At the outset of the study, a pilot study was conducted. To meet the requirement of the pilot, first, 50 participants were chosen from three countries namely UK, UAE, and Malaysia. The purpose of this pilot survey was to get direct feedback from respondents. At this stage, for the questionnaire, it was necessary to assure a feasible, valid and reliable indication of participants' personality traits. In the main study, the process of data gathering was completed in which the filled questionnaires, academic IELTS certificates, and academic reports of the participants were collected.

\section{RESULTS}

In pilot study, while Cronbach's Alpha of 0.740 was achieved for the reliability of the questionnaire, the result of factor analysis led to the elimination of items 14, 38, 40, 42, and 49 to increase the validity of the questionnaire. In addition to the reliability estimation of the questionnaire in the pilot study, in the main study, the Point Biserial correlation was also used.

As there were parametric and non-parametric correlation studies available, it was deemed fit that tests of normality should be carried out. Thus, the Shapiro-Wilk test of normality was carried out on participants' answers to the questionnaire. In order to ensure the sampling adequacy of the Five-Factor personality questionnaire in the main study, the calculations went through the KMO and Bartlett's Test. According to the sampling adequacy requirements, a KMO measure higher than 0.55 is the accepted level of adequacy of any sample. As depicted in table 2 the KMO measure indicated 0.712 , therefore the requirement of the sampling adequacy was met.

TABLE 2.

KMO AND BARTLETT's TEST

\begin{tabular}{|l|l|l|}
\hline Kaiser-Meyer-Olkin Measure of Sampling Adequacy. & .712 \\
\hline \multirow{3}{*}{ Bartlett's Test of Sphericity } & Approx. Chi-Square & 12769.564 \\
\cline { 2 - 3 } & Df & 1225 \\
\cline { 2 - 3 } & Sig. & .000 \\
\hline
\end{tabular}

\section{Hypothesis One}

In order to investigate the predictive power of the components of the Big-Five questionnaire, a standard multiple regression test was put into use. The correlation results amongst the independent variables are presented in table 3 . As the results displayed, the correlation between the independent variables is so high that according to Pallant (2011), it is better not to include the variables that have bigger than 0.7 correlation coefficients. Under these circumstances, "you may need to consider omitting one of the variables or forming a composite variable from the scores of the highly correlated variables" (p. 158). In this way, it was appropriate to form a composite variable of Extraversion, Agreeableness, Conscientiousness, and Openness. Then, the only resulting variables were the composite variable and Neuroticism.

TABLE 3.

CORRELATIONS AMONGST THE COMPONENTS OF THE BIG-FIVE

\begin{tabular}{|c|c|c|c|c|c|c|c|}
\hline & & IELTS & Agreeableness & Conscientiousness & Extroversion & Neuroticism & Openness \\
\hline \multirow{6}{*}{ Pearson Correlation } & IELTS & 1.000 & .869 & .825 & .866 & -.736 & .744 \\
\hline & Agreeableness & .869 & 1.000 & .878 & .908 & -.736 & .798 \\
\hline & Conscientiousness & .825 & .878 & 1.000 & .884 & -.744 & .828 \\
\hline & Extroversion & .866 & .908 & .884 & 1.000 & -.845 & .833 \\
\hline & Neuroticism & -.736 & -.736 & -.744 & -.845 & 1.000 & -.744 \\
\hline & Openness & .744 & .798 & .828 & .833 & -.744 & 1.000 \\
\hline \multirow{6}{*}{ Sig. (1-tailed) } & IELTS & . & .000 & .000 & .000 & .000 & .000 \\
\hline & Agreeableness & .000 &. & .000 & .000 & .000 & .000 \\
\hline & Conscientiousness & .000 & .000 &. & .000 & .000 & .000 \\
\hline & Extroversion & .000 & .000 & .000 &. & .000 & .000 \\
\hline & Neuroticism & .000 & .000 & .000 & .000 &. & .000 \\
\hline & Openness & .000 & .000 & .000 & .000 & .000 &. \\
\hline \multirow{6}{*}{$\mathrm{N}$} & IELTS & 199 & 199 & 199 & 199 & 199 & 199 \\
\hline & Agreeableness & 199 & 199 & 199 & 199 & 199 & 199 \\
\hline & Conscientiousness & 199 & 199 & 199 & 199 & 199 & 199 \\
\hline & Extroversion & 199 & 199 & 199 & 199 & 199 & 199 \\
\hline & Neuroticism & 199 & 199 & 199 & 199 & 199 & 199 \\
\hline & Openness & 199 & 199 & 199 & 199 & 199 & 199 \\
\hline
\end{tabular}

After making the changes to the components of the Big-Five, a linear multiple regression was used to assess the ability of two control measures (composite traits and Neuroticism) to predict levels of English proficiency. Preliminary analyses were conducted to ensure no violation of the assumptions of normality, linearity, multicollinearity and homoscedasticity. The findings of the regression (Table 4) indicated that the composite personality traits had a large and positive predictive power in participants' English proficiency as measured by the IELTS (beta $=0.847, \mathrm{p}<.001$ ). Meanwhile, Neuroticism had a negative and small predictive power in participants' English proficiency as measured by the IELTS $($ beta $=-.041, \mathrm{p}<.001)$. 
TABLE 4.

LineAR MultiPle Regression AMONG COMPOSITE TRAits, NEUROTICISM AND LANGUAGE PROFICIENCY

Coefficients $^{\mathrm{a}}$

\begin{tabular}{|c|c|c|c|c|c|c|c|c|c|c|c|c|c|}
\hline \multirow{2}{*}{\multicolumn{2}{|c|}{ Model }} & \multicolumn{2}{|c|}{$\begin{array}{l}\text { Unstandardized } \\
\text { Coefficients }\end{array}$} & \multirow{2}{*}{\begin{tabular}{|l} 
Standardized \\
Coefficients \\
Beta
\end{tabular}} & \multirow[t]{2}{*}{$\mathrm{T}$} & \multirow[t]{2}{*}{ Sig. } & \multicolumn{2}{|c|}{$\begin{array}{l}95.0 \% \text { Confidence } \\
\text { Interval for B }\end{array}$} & \multicolumn{3}{|c|}{ Correlations } & \multicolumn{2}{|c|}{ Collinearity Statistics } \\
\hline & & $\mathrm{B}$ & Std. Error & & & & $\begin{array}{l}\text { Lower } \\
\text { Bound }\end{array}$ & $\begin{array}{l}\text { Upper } \\
\text { Bound }\end{array}$ & $\begin{array}{l}\text { Zero- } \\
\text { order }\end{array}$ & Partial & Part & Tolerance & VIF \\
\hline \multirow{3}{*}{1} & (Constant) & 2.852 & 647 & & 4.411 & .000 & 1.577 & 4.127 & & & & & \\
\hline & Neuroticism & -.010 & .014 & -.041 & -.700 & .485 & -.037 & .018 & -.736 & -.050 & -.024 & .327 & 3.062 \\
\hline & Composite & .031 & .002 & .847 & 14.330 & .000 & .026 & .035 & .881 & .715 & .484 & .327 & 3.062 \\
\hline
\end{tabular}

In this way, it can be stated that the first null hypothesis was rejected; that is, there is a significant relationship between Big-Five personality traits, except for Neuroticism, and language proficiency scores on IELTS of Iranian foreign students, and each of the four traits had a direct relationship on the overall proficiency of the Iranian students as measured by the IELTS scores. It means that out of Big-Five personality traits only Neuroticism was found not to be directly related to the improvements of language proficiency scores on IELTS.

The relationship between each trait with Iranian foreign students' proficiency scores on IELTS was investigated using Spearman rho correlation coefficient. Preliminary analyses were performed, and it was concluded that a nonparametric correlation test put into use. The results indicated that:

1. There was a high, positive correlation between the two variables of extroversion and IELTS scores; rho $=0.870, n$ $=202, p<.0005$ with scores in the Extroversion items explained $75 \%$ of the variance in the participants' scores on the IELTS. It means that the more Extroverted students the higher scores on IELTS they got.

2. There was a high, positive correlation between the two variables of Agreeableness and IELTS scores; $r h o=0.860$, $n=202, p<.0005$, with scores in the Agreeableness items explaining $73 \%$ of the variance in the participants' scores on the IELTS test. In other words, the students enjoying the high level of Agreeableness could achieve higher scores on the IELTS.

3. There was a high, positive correlation between the two variables of Conscientiousness and IELTS scores; rho $=$ $0.832, n=202, p<.0005$, with scores in the Conscientiousness items explaining $67 \%$ of the variance in the participants' scores on the IELTS test. The results indicated that the more Conscientious the students the higher scores received on the IELTS.

4. There was a high, positive correlation between the two variables of Openness to experience and IELTS scores; rho $=0.735, n=202, p<.0005$, with scores in the Openness to experience items in the Big-Five questionnaire explaining $54 \%$ of the variance in the participants' scores on the IELTS test. It could be stated that when open to experience, students scored higher on IELTS.

5. There was a high, negative correlation between the two variables of Neuroticism and IELTS scores; rho $=-0.706$, $n=202, p<.0005$. In this way, participants' answers to the questionnaire items on Neuroticism were negatively correlated with their IELTS scores. It means that students with emotional stability did not necessarily score well on the IELTS.

\section{Hypothesis Two}

In order to investigate the predictive power of the components of the Big-Five questionnaire, a standard multiple regression test was put into use. The correlation results amongst the independent variables are presented in table 5. As displayed by the results, Given that the correlation between the independent variables is so high as testing the first hypothesis, here it was also appropriate to form a composite variable of Agreeableness (V1), Conscientiousness (V2), Extroversion (V3), and Openness (V4). In this way, the only resulting variables were the composite variable and Neuroticism. 
TABLE 5.

CORRELATIONS AMONGST THE COMPONENTS OF THE BIG-FIVE

\begin{tabular}{|c|c|c|c|c|c|c|c|}
\hline & & Success & v1 & v2 & v3 & Neuroticism & $\mathrm{v} 4$ \\
\hline \multirow{6}{*}{ Pearson Correlation } & Success & 1.000 & .780 & .797 & .816 & -.686 & .659 \\
\hline & $\mathrm{v} 1$ & .780 & 1.000 & .878 & .908 & -.736 & .798 \\
\hline & v2 & .797 & .878 & 1.000 & .884 & -.744 & .828 \\
\hline & v3 & .816 & .908 & .884 & 1.000 & -.845 & .833 \\
\hline & Neuroticism & -.686 & -.736 & -.744 & -.845 & 1.000 & -.744 \\
\hline & v4 & .659 & .798 & .828 & .833 & -.744 & 1.000 \\
\hline \multirow{6}{*}{ Sig. (1-tailed) } & Success & . & .000 & .000 & .000 & .000 & .000 \\
\hline & v1 & .000 & . & .000 & .000 & .000 & .000 \\
\hline & $\mathrm{v} 2$ & .000 & .000 & . & .000 & .000 & .000 \\
\hline & v3 & .000 & .000 & .000 & . & .000 & .000 \\
\hline & Neuroticism & .000 & .000 & .000 & .000 &. & .000 \\
\hline & $\mathrm{v} 4$ & .000 & .000 & .000 & .000 & .000 & . \\
\hline \multirow{6}{*}{$\mathrm{N}$} & Success & 199 & 199 & 199 & 199 & 199 & 199 \\
\hline & v1 & 199 & 199 & 199 & 199 & 199 & 199 \\
\hline & v2 & 199 & 199 & 199 & 199 & 199 & 199 \\
\hline & v3 & 199 & 199 & 199 & 199 & 199 & 199 \\
\hline & Neuroticism & 199 & 199 & 199 & 199 & 199 & 199 \\
\hline & $\mathrm{v} 4$ & 199 & 199 & 199 & 199 & 199 & 199 \\
\hline
\end{tabular}

After making the changes to the components of the Big-Five, a linear multiple regression was used to assess the ability of two control measures (composite traits and Neuroticism) to predict levels of English proficiency. Preliminary analyses were conducted to ensure no violation of the assumptions of normality, linearity, multicollinearity and homoscedasticity. The findings of the regression (Table 6) demonstrated that the composite personality traits had a large and positive predictive power in participants' academic success (beta $=0.774, \mathrm{p}<.001$ ). Meanwhile, Neuroticism made no significant, unique contribution to the prediction of participants' academic success (beta= -.051, p>.001).

TABLE 6.

LiNEAR MUlTIPLE REGRESSION AMONG COMPOSITE TRAITS, NEUROTICISM AND ACADEMIC SUCCESS

\begin{tabular}{|c|c|c|c|c|c|c|c|c|c|c|c|c|c|}
\hline \multirow{2}{*}{\multicolumn{2}{|c|}{ Model }} & \multicolumn{2}{|c|}{$\begin{array}{l}\text { Unstandardized } \\
\text { Coefficients }\end{array}$} & \multirow{2}{*}{$\begin{array}{l}\text { Standardized } \\
\text { Coefficients } \\
\text { Beta }\end{array}$} & \multirow{2}{*}{$\mathrm{T}$} & \multirow{2}{*}{ Sig. } & \multicolumn{2}{|c|}{$\begin{array}{l}95.0 \% \text { Confidence } \\
\text { Interval for B }\end{array}$} & \multicolumn{3}{|c|}{ Correlations } & \multicolumn{2}{|c|}{ Collinearity Statistics } \\
\hline & & B & $\begin{array}{l}\text { Std. } \\
\text { Error }\end{array}$ & & & & $\begin{array}{l}\text { Lower } \\
\text { Bound }\end{array}$ & $\begin{array}{l}\text { Upper } \\
\text { Bound }\end{array}$ & $\begin{array}{l}\text { Zero- } \\
\text { order }\end{array}$ & Partial & Part & Tolerance & VIF \\
\hline \multirow{3}{*}{1} & (Constant) & -.804 & 1.001 & & -.804 & .423 & -2.778 & 1.169 & & & & & \\
\hline & Neuroticism & -.015 & .022 & -.051 & -.711 & .478 & -.058 & .027 & -.686 & -.051 & -.029 & .327 & 3.062 \\
\hline & Composite & .036 & .003 & .774 & 10.723 & .000 & .029 & .042 & .816 & .608 & .442 & .327 & 3.062 \\
\hline
\end{tabular}

Therefore, it can be stated that the null hypothesis as there is not any significant relationship between Big-Five personality traits and academic success of Iranian foreign students was rejected as four of the Big-Five traits had a direct relationship with the overall academic success of the Iranian students. Then, according to the results students with high level of Extroversion, Agreeableness, Conscientiousness, and Openness to experience were able to achieve higher levels of academic success.

The relationship between each trait with academic success of Iranian foreign students was investigated using Spearman rho correlation coefficient. Preliminary analyses were performed, and it was concluded that a non-parametric correlation test had to put into use. There results indicated that:

1. There was a high, positive correlation between the two variables of Extroversion and academic success; rho = $0.808, n=202, p<.0005$, with high scores in the Extroversion items explaining $65 \%$ of the variance in the participants' academic success. Thus, extroverted students could have higher levels of academic success.

2. There was a high, positive correlation between the two variables of Agreeableness and academic success; rho = $0.738, \mathrm{n}=202, p<.0005$, with high scores in the Agreeableness items explaining $54 \%$ of the variance in the participants' academic success. As a result, students with better traces of Agreeableness had higher academic success.

3. There was a high, positive correlation between the two variables of Conscientiousness and academic success; rho $=0.779, n=202, p<.0005$, with high scores in Conscientiousness items explaining $60 \%$ of the variance in the participants' academic success. It means that the more Conscientious the students were, the higher did they achieve the academic success.

4. There was a high, positive correlation between the two variables of Openness to experience and academic success; $r h o=0.599, n=202, p<.0005$, with high scores in Openness to experience items explaining $36 \%$ of the variance in the participants' academic success. Subsequently, the students who were open to experience did have higher academic success.

5. There was a high, negative correlation between the two variables of Neurotisism and academic success, rho $=-$ $0.706, n=202, p<.0005$. In this way, participants' answers to the questionnaire items on Neuroticism were negatively correlated with their academic success. Put another way, students with Neuroticism could not take benefit from such a trait to obtain better academic success. 


\section{Hypothesis Three}

The relationship between academic success and language proficiency of Iranian foreign students was investigated using Spearman rho correlation coefficient. Preliminary analyses were performed, and it was concluded that a nonparametric correlation test put into use. There results (Table 7) illustrated that there was a strong, positive correlation between the two variables, rho $=0.794, n=202, p<.0005$, with high scores in the Big-Five test explaining $63 \%$ of the variance in the participants' academic success. As a result, the null hypothesis as there is not any significant relationship between academic success language proficiency scores on IELTS of Iranian foreign students was rejected. That is to say, the learners who had received better test performance in language proficiency had higher academic success.

TABLE 7.

CORRELATION TEST BETWEen ACADEMIC SUCCESS AND LANGUAGE PROFICIENCY

\begin{tabular}{|c|c|c|c|c|}
\hline & & & IELTS & Success \\
\hline \multirow{6}{*}{ Spearman's rho } & \multirow{3}{*}{ IELTS } & Correlation Coefficient & 1.000 & $.794^{* *}$ \\
\hline & & Sig. (2-tailed) & t & .000 \\
\hline & & $\mathrm{N}$ & 202 & 202 \\
\hline & \multirow{3}{*}{ Success } & Correlation Coefficient & $794^{* *}$ & 1.000 \\
\hline & & Sig. (2-tailed) & .000 & . \\
\hline & & $\mathrm{N}$ & 202 & 202 \\
\hline
\end{tabular}

\section{Four}

To investigate the causality among Big-Five personality traits, the IELTS scores and academic success of Iranian foreign students a canonical model of correlation was put into use. Five predictor variables were Extraversion, Agreeableness, Conscientiousness, Openness to Experience, and Neuroticism. The dependent variables were the English proficiency scores on IELTS and academic success. Wilk's test of significance (Table 8) indicated the general fit of the model for this purpose (Sig. <0.05).

TABLE 8.

WIKIN'S TEST FOR THE GOODNESS OF FIT

\begin{tabular}{|l|l|l|l|l|l|}
\hline Test Name & Value & Approx. F & Hypoth. DF & Error DF & Sig. of F \\
\hline Pillais & .89217 & 31.56924 & 10.00 & 392.00 & .000 \\
\hline Hotellings & 4.61331 & 89.49828 & 10.00 & 388.00 & .000 \\
\hline Wilks & .16751 & 56.28804 & 10.00 & 390.00 & .000 \\
\hline Roys & .81932 & & & \\
\hline Note. F statistic for WILKS' Lambda is exact. & \multicolumn{5}{l|}{} \\
\hline
\end{tabular}

Table 9 reports the canonical correlation coefficients and the eigenvalues of the canonical roots. The first canonical correlation coefficient was .90516 with an explained variance of the correlation of $98.29 \%$ and an eigenvalue of 4.53474. Thus, the null hypothesis as there is not any significant causality among Big-Five personality traits, language proficiency scores on IELTS, and academic success of Iranian foreign students was rejected indicating that generally the Big-Five personality traits, the IELTS test scores, as well as academic success of Iranian foreign students were positively correlated in causality mode. Then, regarding the results of the study, the Big-Five personality traits could predict the quality of performance of Iranian foreign students on both IELTS and academic success.

TABLE 9.

EIGENVALUES AND CANONICAL CORRELATIONS

\begin{tabular}{|l|l|l|l|l|l|}
\hline \multicolumn{6}{|l|}{ Eigenvalues and Canonical Correlations } \\
\hline Root No. & Eigenvalue & Pct. & Cum. Pct. & Canon Cor. & Sq. Cor \\
\hline 1 & 4.53474 & 98.29677 & 98.29677 & .90516 & .81932 \\
\hline 2 & .07858 & 1.70323 & 100.00000 & .26991 & .07285 \\
\hline
\end{tabular}

Table 10 tests the significance of each of the roots. We found that the two possible roots were both significant with $\mathrm{p}$ $<.05$. Since our model contains the two test scores (the IELTS and the academic success) and five personality traits in Big-Five, SPSS extracts two canonical roots or dimensions. The first test of significance tests both canonical roots of significance $(\mathrm{f}=56.289 \mathrm{p}<.05$ ), the second test excludes the first root and tests root two. In our model the first root is and second roots are significant $\mathrm{p}<.05$.

TABLE 10.

DIMENSION REDUCTION ANALYSIS

\begin{tabular}{|c|c|c|c|c|c|}
\hline \multicolumn{6}{|c|}{ Dimension Reduction Analysis } \\
\hline Roots & Wilks L. & $\mathrm{F}$ & Hypoth. DF & Error DF & Sig. of \\
\hline $1 \mathrm{TO} 2$ & .16751 & 56.28804 & 10.00 & 390.00 & .000 \\
\hline $2 \mathrm{TO} 2$ & .92715 & 3.85019 & 4.00 & 196.00 & .005 \\
\hline
\end{tabular}

Table 11 provides the report on the standardized canonical coefficient (mean $=0$, st.dev. $=1$ ). 
TABLE 11.

\begin{tabular}{|lll|} 
STANDARDIZED CANONICAL COEFFICIENTS FOR DEPENDENT VARIABLES \\
\hline Variable & 1 & 2 \\
Conscious & -.33366 & 1.42467 \\
Agreed & -.16678 & -1.37049 \\
Extroverted & -.59625 & .88865 \\
Neurotic & .03349 & .01777 \\
Openness & .09202 & -1.19082 \\
\hline
\end{tabular}

Table 12 provides information on the predictive power of each of the components of the Big-Five on the dependent variables, the IETLS and academic success. In what follows, the predictive power of each component of the Big-Five with the IELTS test and the academic success test is reported.

TABLE 12.

VARIANCE IN DEPENDENT VARIABLES EXPLAINED BY CANONICAL VARIABLES

\begin{tabular}{|l|l|l|l|l|}
\hline CAN. VAR. & Pct Var DEP & Cum Pct DEP & Pct Var COV & Cum Pct COV \\
\hline 1 & 80.40403 & 80.40403 & 65.87687 & 65.87687 \\
\hline 2 & 4.66616 & 85.07018 & .33993 & 66.21680 \\
\hline
\end{tabular}

The degree of prediction of each trait was also tested. Findings of the regression indicated that:

1. Extroversion had a high and positive correlation with participants' English proficiency as measured by the IELTS (beta $=0.597, p<.001$ ). In this way, Extroversion can explain 59\% of variance of the IELTS scores. By the same token, Extroversion had a large and positive correlation with participants' academic success as measured by the academic success index (beta $=0.332, \mathrm{p}<.001$ ). In this way, Extroversion could explain $33 \%$ of variance in academic success scores. In other words, extroverted foreign students were predicted to get higher IELTS scores and succeed in their academic programs.

2. Agreeableness had a high and positive correlation with participants' English proficiency as measured by the IELTS (beta $=0.696, p<.001$ ). In this way, Agreeableness could explain $69 \%$ of variance of the IELTS scores. By the same token, Agreeableness had a positive correlation with participants' academic success as measured by the academic success index (beta $=0.134, p<.001$ ). In this way, Agreeableness can explain $13 \%$ of variance in IELTS in academic success which means that Agreeableness could predict the IELTS test scores and the academic success of Iranian foreign students. Therefore, foreign students with the ability to agree with the others were predicted to score better on IELTS and get successful in their academic education.

3. Conscientiousness had a high and positive predictive correlation with participants' English proficiency as measured by the IELTS (beta $=0.537, \mathrm{p}<.001$ ). In this way, Conscientiousness could explain $53 \%$ of variance of IELTS scores. By the same token, Conscientiousness had a large and positive correlation with participants' academic success as measured by the academic success index (beta $=0.362, \mathrm{p}<.001$ ).

In this way, Conscientiousness could explain $36 \%$ of variance in academic success. Thus Conscientiousness was the predictor of the IELTS test scores and the academic success of Iranian foreign students. In other words, Conscientious foreign students were predicted to achieve better scores on IELTS and do succeed in their academic education.

4. Openness to experience had a high and positive correlation with participants' English proficiency as measured by the IELTS (beta $=0.630, \mathrm{p}<.001$ ). In this way, Openness could explain 63\% of variance of the IELTS scores. Meanwhile, Openness cannot explain any of participants' academic success variation as measured by the academic success index (beta $=0.148, \mathrm{p}<.059$ ) which is indicated that Openness to experience was able to predict the IELTS scores but not the academic success of Iranian foreign students. Therefore, foreign students with the ability to being open to experience were predicted to score better on IELTS. However, it was not a predictor of their academic success.

5. Neuroticism had a large and negative correlation with participants' English proficiency as measured by the IELTS (beta $=-0.513, \mathrm{p}<.001$ ). In this way, Neuroticism could explain $51 \%$ of variance of the IELTS scores. By the same token, Neuroticism had a large and positive predictive power on participants' academic success as measured by the academic success index (beta $=-.270, \mathrm{p}<.001$ ). In this way, Neuroticism could explain $27 \%$ of variance in academic success scores. In this regard, Neuroticism was not the predictor of the IELTS test scores and the academic success of Iranian foreign students. In other words, foreign students who were analyzed to have Neuroticism could not be predicted if to achieve better scores on IELTS and do succeed in their academic education.

\section{DISCUSSION AND CONCLUSION}

The results showed that there were significance relationships amongst four of the Big-Five personality traits and Iranian foreign students' language proficiency scores on IELTS. The findings also revealed that there were significance relationships amongst the Big-Five personality traits and Iranian foreign students' academic success. Finally, it was found that Big-Five personality traits had positive and strong predictive power for both IELTS scores and academic success. However, in all cases Neuroticism or emotional stability was the only component of the Big-Five which was negatively correlated with IELTS scores and academic success and that had no predictive power.

The students who were open to new experiences, able to agree, extroverted, and well careful achieved higher scores on IELTS, and higher levels of academic success. The same four traits were able to predict the scores achieved on 
IELTS and academic courses. Being energetic, optimistic, sociable, kind and enthusiastic, purposeful and determined as well as creative, and imaginative could assist the students to achieve higher scores on language proficiency tests such as IELTS. Findings of the study emphasized that sociable, optimistic and cheerful students could take benefit from such traits when performing the proficiency tests, IELTS in particular. The findings are parallel with Ghapanchi, Khajavy, and Asadpour (2011), Furnham, Chamorro-Premuzic, and McDougall (2002). However, Pazouki and Rastegar (2009) found that being friendly and active, but domineering does not necessarily lead the candidates in proficiency tests to get higher scores. In addition, Zabihi (2011) found possessing such traits (sociable and optimistic) would not make a meaningful difference in students' test performance.

As found in this study, the Big-Five personality traits were directly related with the overall academic success of the Iranian students which is in agreement with the findings of the results of the study of Komarraju, Karau, Schmeck, and Avdic (2011), and Poropat (2009), by which academic performance was found to correlate significantly with Agreeableness, Conscientiousness, and Openness. However, the study by Noftle and Robins (2007) reported Openness was totally weakly associated with academic performance and Zabihi (2011) who found Extroversion to be negatively related though.

Among the findings of the study was the predictive ability of IELTS proficiency test regarding the academic success due to the significant relationship found between language proficiency and academic success of students. This is aligned with the findings of the studies by Dooey and Oliver (2002), Feast (2002), Woodrow (2006), and Yen and Kuzma (2009).

In theoretical respects, the conclusion safely arrives here is that the significant relationship exist between the BigFive personality traits (Extraversion, Agreeableness, Conscientiousness, Openness to Experience, and Neuroticism) and language proficiency scores on IELTS as well as their academic success of Iranian foreign students. Besides, the study showed the same traits would be able to stand as the predictors of both higher scores on IELTS and academic courses. At practical level, it could be concluded that once the students are more open to experience, ready to agree with the others, prepared to perform more conscientiously, and able to act extrovertly, they achieve higher scores both in IELTS and their academic education, and holding such personal traits would be considered as a predictor for better performance on IELTS and academic education.

In terms of this conclusion, reference must be made to Constructivists' points of views as they put forward how an individual learner connects and understands his/her learning conditions is totally personal and these are the learners who determine the quality of learning by their individual features (Williams \& Burden, 2000). The conclusion is also supported by Dornyei \& Skehan (2003) who explain, in terms of learning styles, cognitive sides or the preferred or habitual patterns of mental functioning are important in how well one learns. This is also parallel with Roberts and Meyer (2012) believing in that in order to pick out and direct learners as well as detect those who may need especial types of intervention, it would be really fruitful to be able to foretell how well and how fast an individual learner will learn a second language and which type of teaching would suit them best.

The study concluded that the relation exists between the Big-Five personality traits and academic success of Iranian foreign students. The conclusion is supported by Ellis (2004) who asserts that individual difference research was to foretell which learners would succeed. Such conclusion coupled with Gass and Selinker (2008) maintaining that some students are more successful in learning a second language than others owing to various reasons most of which are not linked to language or psycholinguistic factors, but to the individual him/herself.

This also advocated by Ellis (2008) in that personality traits largely motivated by the needs of learners in need of foreign language instruction as such traits are able to predict which learners would be successful.

It seems that Iranian EFL classes should not take the individual differences for granted and instead to rely on them as predictive tools in recognizing appropriate learning strategies to promote the personality traits and to boost IELTS scores and academic success eventually.

\section{REFERENCES}

[1] Anderson, M. (1992). Intelligence and development: A cognitive theory. Blackwell Publishing.

[2] Arnold, J. (Ed.). (1999). Affect in langauge learning.Cambridge: Cambridge University Press.

[3] Ausubel, D. P. (2012). The acquisition and retention of knowledge: A cognitive view. Springer Science \& Business Media.

[4] Bayliss, A. \& Ingram, D. E. (2006) IELTS as a Predictor of Academic Language Performance, Australian International Education Conference 2006. pp 1-12.

[5] Brody, N. (2000). History of theories and measurements of intelligence. Handbook of intelligence, 16-33.

[6] Busato, V. V., Prins, F. J., Elshout, J. J., \& Hamaker, C. (2000). Intellectual ability, learning style, personality, achievement motivation and academic success of psychology students in higher education. Personality and Individual differences, 29(6), 1057-1068.

[7] Chamorro-Premuzic, T., \& Furnham, A. (2003). Personality traits and academic examination performance. European Journal of Personality, 17(3), 237-250.

[8] Costa, P.T. Jr, \& McCrae, R.R. (1988). Personality in adulthood: A six year longitudinal study of self-reports and spouse rating on the NEO Personality Inventory. Journal of Personality \& Social Psychology, 54(5), 853-863.

[9] Costa, P. T, \& McCrae, R. (1992). Revised NEO Personality Inventory (NEO-PI-R) and NEO Five-Factor Inventory (NEOFFI): Professional manual. Odessa, FL: Psychological Assessment Resources. 
[10] Costa, P. T., \& McCrae, R. R. (1995). Solid ground in the wetlands of personality: A reply to Block. Psychological Bulletin, $117,216-220$.

[11] Cronbach, L. J. (1949). Essentials of psychological testing. Oxford: Harper.

[12] De Raad, B., \& Schouwenburg, H. C. (1996). Personality in learning and education: A review. European Journal of Personality, 10(5), 303-336.

[13] Dooey, P., \& Oliver, R. (2002). An investigation into the predictive validity of the IELTS Test as an indicator of future academic success. Prospect, 17(1), 36-54.

[14] Dörnyei, Z. \& Skehan, P. (2003) 'Individual differences in second language learning'. In C.J. Doughty \& M.H. Long (Eds.), The Handbook of Second Language Acquisition (pp. 589-630. Oxford: Blackwell.

[15] Dörnyei, Z. (2005). The psychology of the language learner individual differences in second language acquisition. New Jersey: Lawrence Elbaum Associates.

[16] Duff, A., Boyle, E., Dunleavy, K., \& Ferguson, J. (2004). The relationship between personality, approach to learning and academic performance. Personality and Individual Differences, 36(8), 1907-1920.

[17] Ehrman, M. E., Leaver, B. L., \& Oxford, R. L. (2003). A brief overview of individual differences in second language learning. System, 31(3), 313-330.

[18] Ellis, R. (2004). 21 Individual Differences in Second Language Learning. In A. Davies and C. Elder (Eds.), The Handbook of Applied Linguistics (pp. 525-551). Oxford: Blackwell.

[19] Ellis, R. (2008). The study of second language acquisition. Oxford: Oxford University Press.

[20] Erdheim, J., Wang, M., \& Zickar, M. J. (2006). Linking the Big-Five personality constructs to organizational commitment. Personality and Individual Differences, 41(5), 959-970.

[21] Feast, V. (2002). The impact of IELTS scores on performance at university. International Education Journal, 3(4), 70-85.

[22] Funder, D.C. (2001). Personality. Annual Review of Psychology, 52(1), 197-221.

[23] Furnham, A. (1996). The FIRO-B, the learning style questionnaire and the five-factor model. Journal of Social Behaviour and Personality, 11(2), 285-299.

[24] Furnham, A., Chamorro-Premuzic, T., \& McDougall, F. (2002). Personality, cognitive ability, and beliefs about intelligence as predictors of academic performance. Learning and Individual Differences, 14(1), 47-64.

[25] Gass, S.M., \& Selinker, L. (2008). Second language acquisition: An introductory course, (3 ${ }^{\text {rd }}$ edition). New York, NY:Routledge.

[26] Ghapanchi, Z., Khajavy, G. H., \& Asadpour, S. F. (2011). L2 motivation and personality as predictors of the Second language proficiency: Role of the Big-Five traits and L2 motivational self System. Canadian Social Science, 7(6), 148-155.

[27] Goldberg, L.R. (1990). An alternative description of personality: The Big-Five factor structure. Journal of Personality \& Social Psychology, 59(6), 1216-1229.

[28] Goldberg, L. R. (1992). The development of markers for the Big-Five factor structure. Psychological Assessment, 4(1), $26-42$.

[29] Goldberg, L. R. (1993). The structure of phenotypic personality traits. American Psychologist, 48(1), 26-34.

[30] Goldberg, L. R. (2001). International Personality Item Pool. Web address can be obtained from authors.

[31] Hogan, R., Hogan, J. \& Roberts, B. W. (1996). Personality measurement and employment decisions: Questions and answers. American Psychologist, 51(5), 469-477.

[32] John, O. P., \& Robins, R. W. (1993). Gordon Allport: Father and critic of the Five-Factor Model. In Craik, K. H., Hogan, R. T., $\&$ Wolfe, R. N. (Eds.), Fifty years of personality research (pp. 215- 236). New York: Plenum.

[33] John, O. P., \& Robins, R. W. (1998). Recent trends in Big-Five research: Development, predictive validity, and personality types. In Bermudez, J. (Eds.), Personality Psychology in Europe (Vol. 6, pp. 6-16). Tilbourg, The Netherlands: Tilbourg University Press.

[34] Judge, T.A., Higgins, C., Thoresen, C.J., \& Barrick, M.R. (1999). The Big-Five personality traits, general mental ability, and career success across the life span. Personal Psychology, 52(3), 621-652. Retrieved from http://people.tamu.edu/ mbarrick/Pubs/ 1999_Judge_Higgins_Thoresen_Barrick.pdf.

[35] Komarraju, M., Karau, S. J., Schmeck, R. R., \& Avdic, A. (2011). The Big Five personality traits, learning styles, and academic achievement. Personality and individual differences, 51(4), 472-477.

[36] McAdams, D. P. \& Pals, J. L. (2006). A new Big-Five: fundamental principles for an integrative science of personality. American Psychologist, 61(3), 204.

[37] McCrae, R.R., Costa, P.T.Jr. (1997). Personality trait structure as a human universal. American Psychologist, 52(2), 509-516.

[38] McLaughlin, B. (1987). Theories of second-language learning. London: Edward Arnold.

[39] Noftle, E. E., \& Robins, R. W. (2007). Personality predictors of academic outcomes: Big-Five correlates of GPA and SAT scores. Journal of personality and social psychology, 93(1), 116.

[40] Pallant, J. (2011). SPSS Survival Manual 4th edition: A step by step guide to data analysis using SPSS version 18. Maidenhead, Berkshire: Open University Press.

[41] Pazouki, M., \& Rastgar, M. (2009). Extraversion-Introversion, shyness, and EFL proficiency. Psychological Research, 12(1).

[42] Poropat, A. E. (2009). A meta-analysis of the five-factor model of personality and academic performance. Psychological bulletin, 135(2), 322

[43] Poropat, A. E. (2011). The Eysenckian personality factors and their correlations with academic performance. British Journal of Educational Psychology, 81(1), 41-58.

[44] Roberts, L., \& Meyer, A. (2012). Individual differences in second language learning: Introduction. Language Learning, 62(s2), $1-4$.

[45] Seyed Erfani, S. (2011). A Comparative Study of Class Activities and Students Expectations of IELTS and TOEFL iBT Preparation Courses: A Methodological Triangulation Washback Study. Journal of English Studies, 1(12), 87-102.

[46] Tarone, E. (2007). Sociolinguistic approaches to second language acquisition research-1997-2007. The Modern Language Journal, 91(s1), 837-848. 
[47] Williams, M., \& Burden, R. (2000). Psychology for language teachers. Beijing: Foreign Language Teaching and Research Press.

[48] Woodrow, L. (2006). Academic success of international postgraduate education students and the role of English proficiency. University of Sydney papers in TESOL, 1(1), 51-70.

[49] Yen, D., \& Kuzma, J. (2009). Higher IELTS score, higher academic performance? The validity of IELTS in predicting the academic performance of Chinese students. Worcester Journal of Learning and Teaching, 3, 1-7.

[50] Zabihi, R. (2011). Personality in English language proficiency and achievement. Wilolud Journals, 4(1), 1-6. Retrieved from http://citeseerx.ist.psu.edu/viewdoc/download? doi=10.1.1.367.8204\&rep=rep1\&type=pdf.

Shiva Seyed Erfani (Correspondence) is an Assistant Professor and a full-time faculty member of English Department at Islamic Azad University, Roudehen Branch, Iran. She received her Ph.D. in English Language Teaching from Allameh Tabataba'i University, Tehran, Iran, M.A. in English Language Teaching and B.A. in English Translation from Islamic Azad University, Central Branch, Tehran, Iran.

Her areas of interest are Language Testing and Assessment, Second Language Acquisition, and CALL, in which she has been teaching for the last two decades and has published articles in local and international scholarly journals of the field.

Hoda Maran is currently a Ph.D. candidate at Allameh Tabatabae'i University, Tehran, Iran. She got her M.A. and B.A. in English Language Teaching from Islamic Azad University, Roudehen Branch, Iran. She has been actively practicing teaching English to EFL learners in different English institutes and organizations in the past 5 years. 